\title{
Disulfide Connectivity Analysis of Peptides Bearing Two Intramolecular Disulfide Bonds Using MALDI In-Source Decay
}

\author{
Philippe Massonnet, ${ }^{1}$ ๑ Jean R. N. Haler,${ }^{1}$ Gregory Upert, ${ }^{2}$ Nicolas Smargiasso, ${ }^{1}$ \\ Gilles Mourier, ${ }^{2}$ Nicolas Gilles, ${ }^{2}$ Loïc Quinton, ${ }^{1}$ Edwin De Pauw ${ }^{1}$ \\ ${ }^{1}$ Mass Spectrometry Laboratory, MolSys Research Unit, University of Liège, Quartier Agora, Allée du six Aout 11, B-4000, Liege, \\ Belgium \\ ${ }^{2}$ Commissariat à l'Energie Atomique, DRF/SIMOPRO, 91191, Gif sur Yvette, France
}

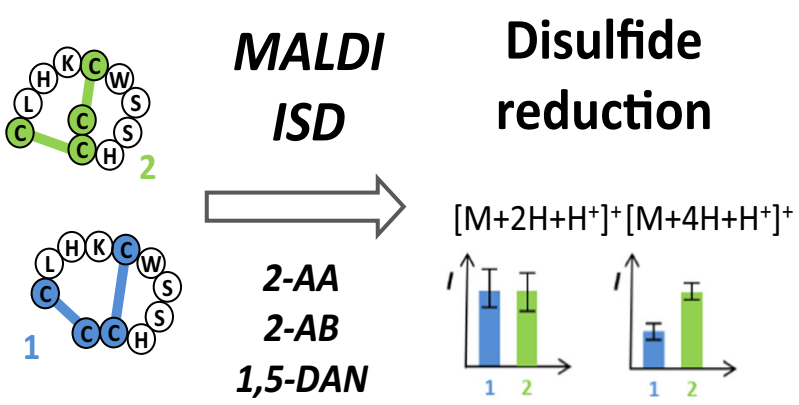

Abstract. Disulfide connectivity in peptides bear-
ing at least two intramolecular disulfide bonds is
highly important for the structure and the biolog-
ical activity of the peptides. In that context, ana-
lytical strategies allowing a characterization of the
cysteine pairing are of prime interest for chemists,
biochemists, and biologists. For that purpose, this
study evaluates the potential of MALDI in-source
decay (ISD) for characterizing cysteine pairs
through the systematic analysis of identical peptides bearing two disulfide bonds, but not the same cysteine connectivity. Three different matrices have been tested in positive and/or in negative mode (1,5-DAN, 2-AB and 2-AA). As MALDI-ISD is known to partially reduce disulfide bonds, the data analysis of this study rests firstly on the deconvolution of the isotope pattern of the parent ions. Moreover, data analysis is also based on the formed fragment ions and their signal intensities. Results from MS/MS-experiments (MALDI-ISD-MS/MS) constitute the last reference for data interpretation. Owing to the combined use of different ISD-promoting matrices, cysteine connectivity identification could be performed on the considered peptides.

Keywords: Mass spectrometry, Peptide, Disulfide bonds, MALDI, ISD, Isomers

Received: 26 February 2018/Revised: 7 May 2018/Accepted: 21 June 2018/Published Online: 9 July 2018

\section{Introduction}

A mong all post-translational modifications, disulfide bonds stand out due to their formation mechanism based on the oxidation of two cysteine residues creating S-S bonds. This modification is for example found in animal venoms [1], cyclotides [2, 3], or again in antimicrobial peptides [4, 5]. Disulfide bonds provide structural constraints to peptide and protein backbones [6-10]. The presence of such bonds can also

Electronic supplementary material The online version of this article (https:// doi.org/10.1007/s13361-018-2022-y) contains supplementary material, which is available to authorized users.

Correspondence to: Philippe Massonnet; e-mail: pmassonnet@uliege.be be mandatory in order to stabilize secondary structures [11-14] such as $\alpha$-helices and $\beta$-sheets, or to maintain a specific biological activity $[2,15]$. For instance, it has been shown that the biological activity of peptides bearing two disulfide bonds can be affected by the cysteine connectivity $\left(\mathrm{C}_{1}-\mathrm{C}_{2} / \mathrm{C}_{3}-\mathrm{C}_{4}, \mathrm{C}_{1}\right.$ $\mathrm{C}_{3}, \mathrm{C}_{2} / \mathrm{C}_{4}, \mathrm{C}_{1}-\mathrm{C}_{4} / \mathrm{C}_{2}-\mathrm{C}_{3}$ ) [16]. Indeed, when having multiple intramolecular disulfide bonds, the number of possible cysteine connectivities rapidly increases with the number of disulfide bonds (relation described by combinatorics) and the biological relevance of the cysteines becomes even more important [17].

In this context, characterization techniques allowing having access to cysteine connectivity are important. For this purpose, NMR-based strategies have been developed [18, 19]. The downsides of NMR are, however, the need for large amounts of sample and, most of the time, the requirement of ${ }^{13} \mathrm{C}$ and/or 
Table 1. List of the peptides used in this study

\begin{tabular}{|c|c|c|}
\hline Name & Sequence & Cysteine connectivity \\
\hline$\alpha$-Conotoxin & $\mathbf{C}_{1} \mathbf{C}_{2} \mathrm{HSSWC}_{3} \mathrm{KHLC}_{4}$ & $\mathrm{C}_{1}-\mathrm{C}_{3} / \mathrm{C}_{2}-\mathrm{C}_{4}$ \\
\hline$\chi$-Conotoxin & $\mathrm{C}_{1} \mathrm{C}_{2} \mathrm{HSSWC}_{3} \mathrm{KHLC}_{4}$ & $\mathrm{C}_{1}-\mathrm{C}_{4} / \mathrm{C}_{2}-\mathrm{C}_{3}$ \\
\hline ModBea & $\mathbf{C}_{1}$ EGWFRFTKTGLEYC $_{2}$ TPGLC $_{3}$ LRWGKLC $_{4}{ }^{*}$ & $\mathrm{C}_{1}-\mathrm{C}_{2} / \mathrm{C}_{3}-\mathrm{C}_{4}$ \\
\hline ModGlo & $\mathbf{C}_{1}$ EGWFRFTKTGLEYC $_{2}$ TPGLC $_{3}$ LRWGKLC $_{4} *$ & $\mathrm{C}_{1}-\mathrm{C}_{3} / \mathrm{C}_{2}-\mathrm{C}_{4}$ \\
\hline ModRib & $\mathbf{C}_{1}$ EGWFRFTKTGLEYC $_{2}$ TPGLC $_{3}$ LRWGKLC $_{4} *$ & $\mathrm{C}_{1}-\mathrm{C}_{4} / \mathrm{C}_{2}-\mathrm{C}_{3}$ \\
\hline
\end{tabular}

*Peptides with a C-terminus amidation

${ }^{15} \mathrm{~N}$-labeled analogues. Techniques involving tryptic digestion and liquid chromatography separations have also been developed [20, 21]. Nevertheless, these techniques are time consuming and not always efficient when there are not enough cleavage sites between the cysteines.

More recently, techniques involving gas-phase reactions have been developed for the characterization of peptides bearing intramolecular disulfide bond(s) [22-25]. The presence of disulfide bonds was for example probed by collision-induced dissociation (CID) [22] and the disulfide connectivties were determined using electron transfer dissociation (ETD) [24, 25]. MALDI in-source decay (ISD) reactivity of disulfide bonds has also been investigated on various peptides [26-32]. These studies pointed out the ability of 1,5-diaminonaphtalene $(1,5$ DAN) matrix to reduce disulfide bonds (addition of two radical hydrogens on the sulfur atoms) and the possibility to determine the number of S-S bonds in a given peptide (from 0 to 3 ). For these studies, peptides containing one disulfide bond were

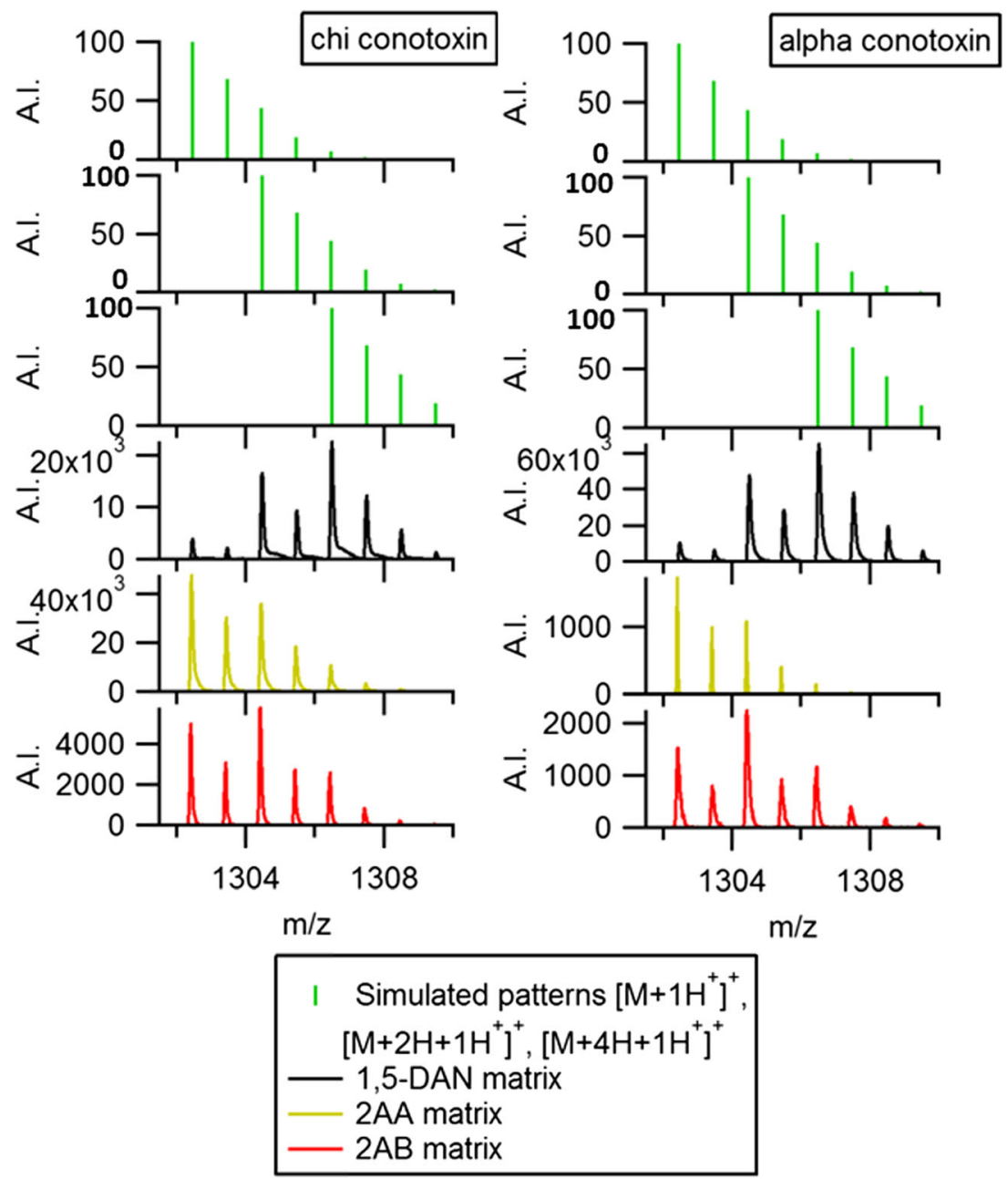

Figure 1. On the left, $1+$ charge state series of $x$-conotoxin using different matrices. On the right, $1+$ charge state series of $\alpha$ conotoxin. The first row (green spectra) represents the simulated isotope pattern without disulfide bond reduction $\left(\left[\mathrm{M}+1 \mathrm{H}^{+}\right]^{+}\right)$. The second and the third rows represent respectively the simulated isotope pattern with 1 disulfide bond reduction $\left(\left[\mathrm{M}+2 \mathrm{H}+1 \mathrm{H}^{+}\right]^{+}\right)$and 2 disulfide bond reductions $\left(\left[\mathrm{M}+4 \mathrm{H}+1 \mathrm{H}^{+}\right]^{+}\right)$. The fourth, fifth, and last rows of spectra represent the isotope patterns of the (reduced) parent ions using respectively the 1,5-DAN (black), 2-AA (yellow), and 2-AB (red) matrices 
mostly investigated as proof of concept. Fukuyama and coworkers studied a peptide with two disulfide bonds using MALDI-ISD followed by CID activation [26]. They concluded that using theoretical and experimental mass differences of fragment ions having reduced or intact disulfide bonds could enable the prediction of the disulfide bond connectivity. However, these hypotheses have not yet been systematically or experimentally surveyed on multiple peptides with identical sequences but differing disulfide bond connectivities.

In this work, we investigate the effects of the cysteine connectivity on disulfide bond reactivity undergoing MALDI-ISD. The reduction and fragmentation capabilities of three ISD matrices are examined: 1,5-diaminonaphtalene (1,5DAN), 2-aminobenzamide (2-AB), and 2-aminobenzoic acid (2-AA). For this purpose, two peptide sequences bearing two disulfide bonds were chosen.

\section{Materials and Methods}

\section{Chemicals and Peptides}

2-Aminobenzamide (2-AB), 2-aminobenzoic acid (2-AA), 1,5diaminonaphthalene (1,5-DAN), and formic acid (FA) were purchased from Sigma-Aldrich (Saint Louis, MO, USA), while acetonitrile (ACN) was purchased from Biosolve (Dieuze, France). 1,5-DAN has been chosen because of its well known high efficiency to reduce disulfide bonds while 2-AA and 2$\mathrm{AB}$ matrices are known to have a lower efficiency to reduce disulfide bonds [28]. The sequences and the connectivities of the peptides used in this study are summarized in Table 1. They were chemically synthetized as previously described [24, 33].

\section{Mass Spectrometry Analysis}

All MALDI mass spectrometry experiments were performed on a rapifleX TOF/TOF mass spectrometer (Bruker Daltonics, Bremen, Germany) equipped with a smartbeam ${ }^{\mathrm{TM}} 3 \mathrm{D}$ laser in positive and/or in negative mode. The analyzer was operated in reflectron mode and all spots were prepared using the dried droplet method: $1 \mu \mathrm{L}$ of peptides at $10 \mu \mathrm{M}$ in a $\mathrm{H}_{2} \mathrm{O} / \mathrm{ACN} / \mathrm{FA}$ 49.9/50/0.1 solvent mixture was first placed on the target plate and allowed to dry at room temperature followed by the deposition of $1 \mu \mathrm{L}$ of matrix solution. The 2-AA and 2-AB matrices were used at a concentration of $20 \mathrm{mg} / \mathrm{mL}$ in a $\mathrm{H}_{2} \mathrm{O} / \mathrm{ACN} / \mathrm{FA}$ 49.9/50/0.1 $(v / v / v)$ while 1,5-DAN was prepared at saturation in the same solvent mixture. Due to the instability of 1,5-DAN in ACN [34], 1,5-DAN solutions were prepared just before mass spectrometry analysis. For the 2-AA and 2-AB matrices, fresh solutions were also used. Each spectrum is a sum of 5000 laser shots (5 times 1000 shots at $1000 \mathrm{~Hz}$ ) at a laser intensity of $40 \%$. A laser intensity of $50 \%$ has been used for the spots containing 2-AA and 2-AB matrices. The detector gain was set to $2.45 \mathrm{kV}$ in the positive mode and to $2.0 \mathrm{kV}$ in negative mode. The measurements of each peptide with each matrix (one peptide/matrix combination per spot) were performed 5 times ( 5 different days) with fresh solutions and matrices on each spot in order to verifiy the reproducibility of the measurements.

\section{MS/MS (CID) Experiments}

For the CID experiments, the MS/MS mode of the rapifleX has been used and the laser intensity was set to $65 \%$. The laser boost was set to $60 \%$ and all presented spectra are constituted by a sum of 10,000 shots ( 10 times 1000 shots at $1000 \mathrm{~Hz}$ ). The collision chamber was filled with Argon.
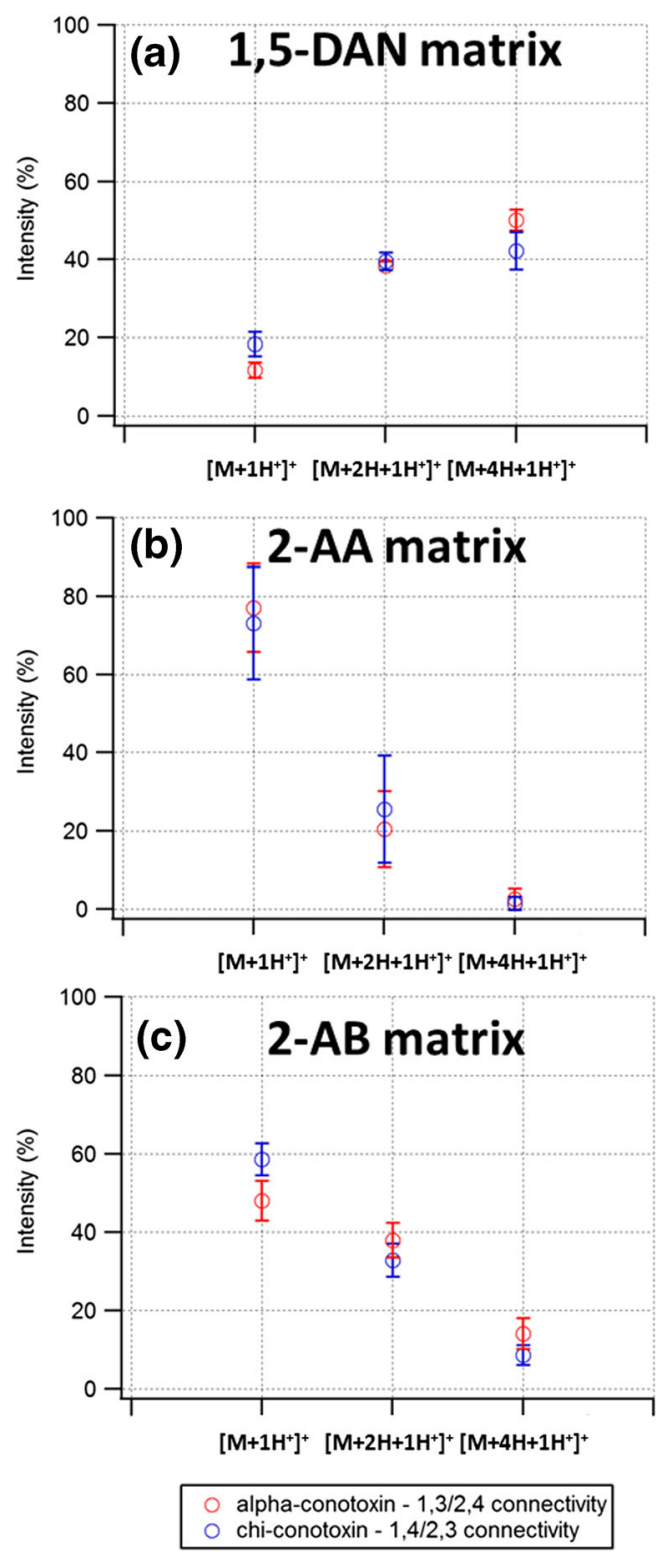

Figure 2. Calculated normalized intensities (see Eq. 1) after isotope pattern deconvolution of the parent ion $\left[\mathrm{M}+1 \mathrm{H}^{+}\right]^{+}$, of the partially reduced parent ion $\left[\mathrm{M}+2 \mathrm{H}+1 \mathrm{H}^{+}\right]^{+}$and the totally reduced species $\left[\mathrm{M}+4 \mathrm{H}+1 \mathrm{H}^{+}\right]^{+}$of the conotoxin-based peptides using (a) the 1,5-DAN matrix; (b) the 2-AA matrix, and (c) 2$\mathrm{AB}$ matrix. The error bars originate from the standard deviation of 5 independent measurements ( 5 different days) 


\section{Data Analysis}

All presented data were extracted using the FlexAnalysis 3.4 (Bruker Daltonics) software while isotope pattern deconvolutions were performed using Microsoft Excel 2010. All figures were generated using Igor Pro 6.37 and FlexAnalysis 3.4.

\section{Results and Discussion}

\section{Peptides Inspired from Conotoxins}

First, the $\alpha$ - and $\chi$-conotoxins are investigated (see Table 1). The comparison of the experimental isotope patterns of the parent ions with the simulated patterns for non-reduced species demonstrates that all the matrices (1,5-DAN, 2-AA, 2-AB) have the ability to reduce disulfide bonds (Figure 1). Disulfide bond reduction modifies the isotope patterns by superimposing signatures of the non-reduced species, of the species that have undergone the reduction of only one disulfide bond (additional 2 mass units) and the ones that are totally reduced (additional 4 mass units). When further analyzing the results, it appears that the 1,5-DAN matrix reduces more efficiently the disulfide bonds than the 2-AA and 2-AB matrices, as already demonstrated in literature [28, 35]. Moreover, when focusing on the fragment ions of both conotoxins using the three matrices (see
Fig. SI 1), only few fragments are observed (losses of $\mathrm{H}_{2} \mathrm{~S}$ and $\mathrm{CH}_{2} \mathrm{~S}_{2}$ as already reported elsewhere $\left.[28,36]\right)$. Based on these results, we have chosen to focus our attention only on the parent ions for the determination of the disulfide bond reduction capabilities of the matrices.

Figure 2 depicts the normalized intensities obtained after isotope pattern deconvolutions of non-reduced $\left(\left[\mathrm{M}+1 \mathrm{H}^{+}\right]^{+}\right.$, see Eq. 1), partially $\left(\left[\mathrm{M}+2 \mathrm{H}+1 \mathrm{H}^{+}\right]^{+}\right)$and totally reduced $\left(\left[\mathrm{M}+4 \mathrm{H}+1 \mathrm{H}^{+}\right]^{+}\right)$species of the two peptides using the three different matrices. Equation 1 illustrates the normalized intensity calculation on the non-reduced parent ion $\left[\mathrm{M}+1 \mathrm{H}^{+}\right]^{+}$. To verify the reproducibility of the data, the MALDI-ISD measurement of each peptide connectivity with each matrix was performed 5 times, summing 5000 laser shots for each replicate measurement.

$$
\begin{aligned}
& \text { Intensity }_{\left[M+1 H^{+}\right]^{+}}(\%)= \\
& \frac{\sum I_{\text {isotope pattern }}\left[M+1 H^{+}\right]^{+}}{\sum I_{\text {isotope pattern }}\left(\left[M+1 H^{+}\right]^{+},\left[M+2 H+1 H^{+}\right]^{+},\left[M+4 H+1 H^{+}\right]^{+}\right)} * 100
\end{aligned}
$$

Figure 2 reveals that the 2-AA matrix yields similar normalized intensities for both conotoxins and all parent ion species (non-reduced, partially reduced, and totally reduced). 2-AA does hence not allow to unambiguously distinguish between the two disulfide connectivities. This behavior is confirmed by

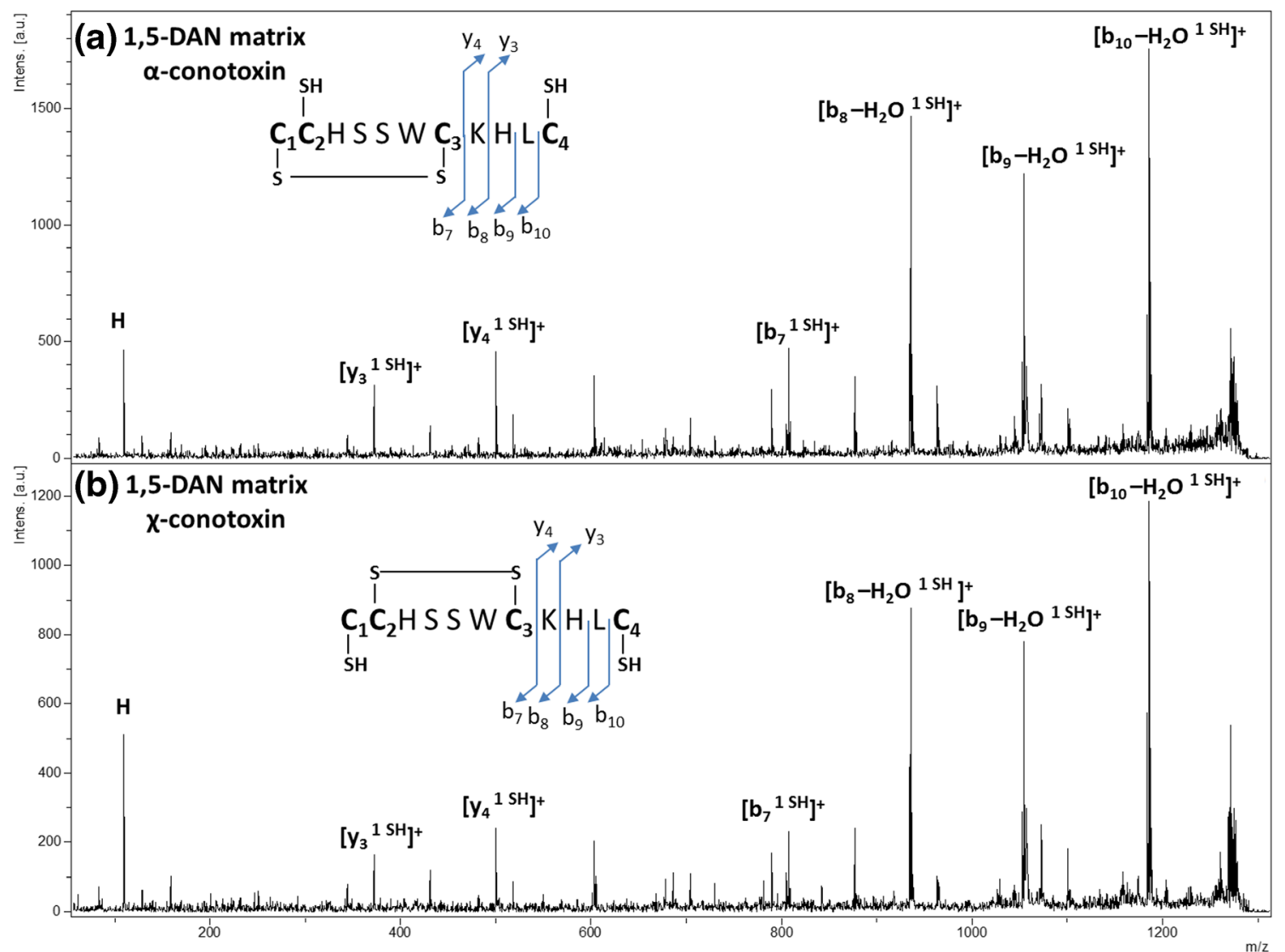

Figure 3. $M S / M S$ (high energy $C I D)$ spectra after isolation of the partially reduced species $\left[M+2 H+1 H^{+}\right]^{+}$of $(a) \alpha-c o n o t o x i n\left(C_{1}\right.$, $\left.\mathrm{C}_{3} / \mathrm{C}_{2}, \mathrm{C}_{4}\right)$ and $(\mathbf{b}) \mathrm{X}$-conotoxin $\left(\mathrm{C}_{1}, \mathrm{C}_{4} / \mathrm{C}_{2}, \mathrm{C}_{3}\right)$ using 1,5-DAN matrix. The fragment ion peaks are annotated with their identities (1 SH designates the presence of one $1 \mathrm{SH}$ in the selected fragment) and a peptide sequence scheme with all the observed fragments for the different disulfide isomers is represented in each spectrum. The spectrum was recorded with a laser boost of $60 \%$ 
the $p$ values obtained after $t$ test (see Figure SI2). Indeed, the obtained $p$ values for the 2-AA matrix are always higher than 0.05 (significant value). However, the connectivities of the two conotoxin isomers are differentiated using the 1,5-DAN and 2$\mathrm{AB}$ matrices. For both matrices, the $\alpha$-conotoxin $\left(\mathrm{C}_{1}-\mathrm{C}_{3} / \mathrm{C}_{2}-\right.$ $\mathrm{C}_{4}$ connectivity) exhibits an increased reactivity towards the ISD process compared to the $\chi$-conotoxin peptide $\left(\mathrm{C}_{1}-\mathrm{C}_{4} /\right.$ $\mathrm{C}_{2}-\mathrm{C}_{3}$ connectivity). This is demonstrated by the smaller normalized intensity of the non-reduced $\alpha$-conotoxin parent ion $\left[\mathrm{M}+1 \mathrm{H}^{+}\right]^{+}$. Again, these discussions are supported by the $p$ values obtained after $t$ tests (see Figure SI3 and Figure SI4). In both cases (2-AB and 1,5 DAN matrices), the $p$ values are lower than 0.05 . By looking at the totally reduced ion species $\left[\mathrm{M}+4 \mathrm{H}+1 \mathrm{H}^{+}\right]^{+}$obtained using 1,5$\mathrm{DAN}$ and 2-AB, the two conotoxins are also clearly distinguishable (see Figure SI3 and Figure SI4; $p$ values $<0.05$ ). These results could be related to an increased accessibility of the disulfide bonds of $\alpha$-conotoxin $\left(\mathrm{C}_{1}-\mathrm{C}_{3} / \mathrm{C}_{2}-\mathrm{C}_{4}\right.$ connectivity) for the radical hydrogens produced by the ISDinducing matrix.

The same measurements were also performed in negative mode using the 1,5-DAN matrix. However, no significant differences are obtained between both connectivity isomers (see Figure SI5 and Figure SI6 for results and $p$ values). This behavior could be explained by a low ionization efficiency resulting in low intensities in the spectra, thus making the signal extraction difficult.

In positive mode, in order to further analyze the partially reduced species, MS/MS (high energy CID) experiments were performed (see Figure 3). Unfortunately, resulting spectra were the same for both conotoxins, avoiding then any distinction between the two species. Indeed, as seen in Figure 3, only fragments between $\mathrm{C}_{3}$ and $\mathrm{C}_{4}$ are obtained in both cases (opening by ISD of the $\mathrm{C}_{2}-\mathrm{C}_{4}$ disulfide bond for the $\alpha$ conotoxin and of the $\mathrm{C}_{1}-\mathrm{C}_{4}$ disulfide bond for the $\chi$-conotoxin).

\section{Model Peptides}

Next, we analyzed three model peptides containing 2 disulfide bridges using the same approach as for the conotoxin-inspired peptides. Figure 4 reveals that all three matrices reduce the disulfide bonds of the mod-based peptides. From Figure 4, the 1,5-DAN matrix seems to reduce more efficiently the disulfide bonds than the two other matrices.

In positive mode, MS/MS (high energy CID) experiments on the non-reduced and partially reduced species were performed (see Figure SI7 and Figure SI8). Unfortunately, resulting spectra were the same for all isomers (see $y_{11}, y_{12}$, $\mathrm{y}_{14}$, and $\mathrm{c}_{14}$ ions). This could be due to the high energy CID that opens disulfide bonds in a similar way for all isomers. (a)

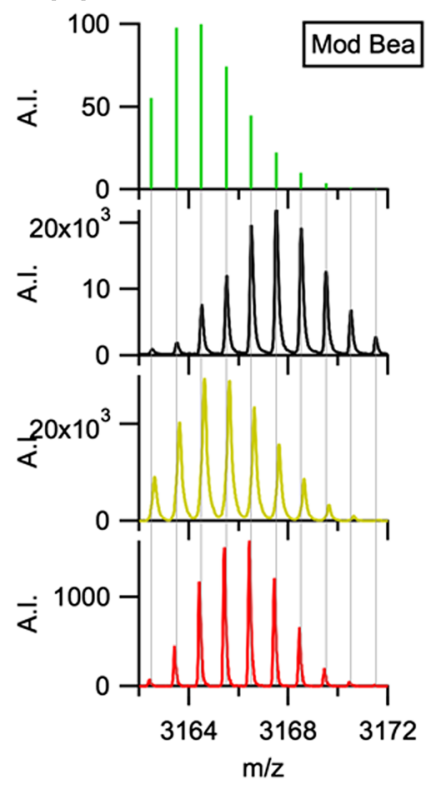

(b)

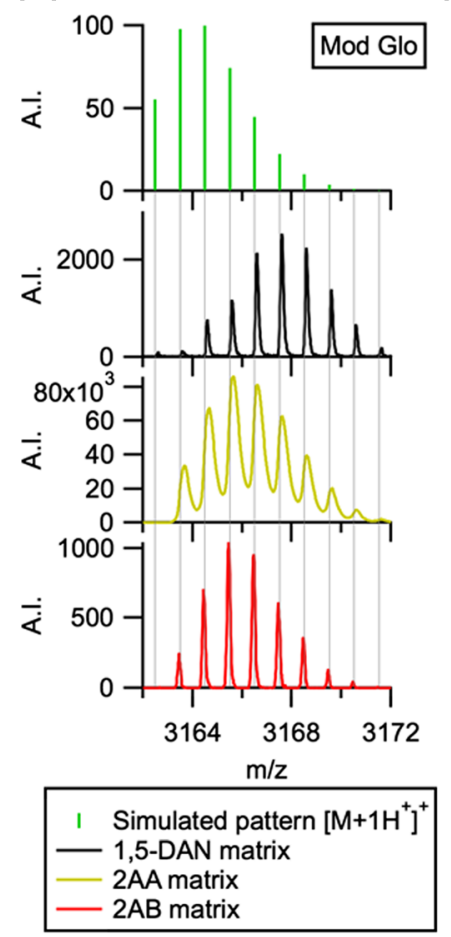

(c)

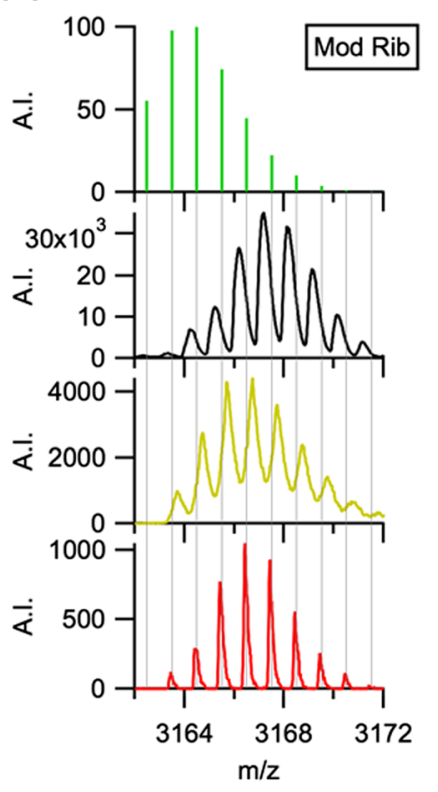

Figure 4. (a) $1+$ charge state series of the ModBea peptide $\left(C_{1}, C_{2} / C_{3}, C_{4}\right.$ connectivity) using different matrices (1,5-DAN in black, 2$\mathrm{AA}$ in yellow, and $2-\mathrm{AB}$ in red) compared with the simulated isotope pattern without reduction $\left(\left[\mathrm{M}+1 \mathrm{H}^{+}\right]^{+}\right.$, green spectrum); (b) $1+$ charge state series of the ModGlo peptide $\left(\mathrm{C}_{1}, \mathrm{C}_{3} / \mathrm{C}_{2}, \mathrm{C}_{4}\right.$ connectivity) using different matrices (1,5-DAN in black, 2-AA in yellow, and $2-A B$ in red) compared with the simulated isotope pattern without reduction $\left(\left[\mathrm{M}+1 \mathrm{H}^{+}\right]^{+}\right.$, green spectrum); (c) $1+$ charge state series of the ModRib peptide $\left(\mathrm{C}_{1}, \mathrm{C}_{4} / \mathrm{C}_{2}, \mathrm{C}_{3}\right.$ connectivity) using different matrices (1,5-DAN in black, 2-AA in yellow, and 2-AB in red) compared with the simulated isotope pattern without reduction $\left(\left[\mathrm{M}+1 \mathrm{H}^{+}\right]^{+}\right.$, green spectrum) 
When focusing on the ISD fragments using 1,5-DAN, Figure SI9 shows small differences between the three isomers. For example, fragment ion peak at $\mathrm{m} / \mathrm{z} 999.4$ is only found for the ModBea isomer $\left(\mathrm{C}_{1}, \mathrm{C}_{2} / \mathrm{C}_{3}, \mathrm{C}_{4}\right.$ connectivity) while the peak at $m / z=2781.7$ (GWFRFTKTGLEYCTPGLCLRWGKL$\left.\mathrm{H}_{2} \mathrm{O}-\mathrm{NH}_{3}\right)$ is only found for the ModGlo isomer $\left(\mathrm{C}_{1}, \mathrm{C}_{3} / \mathrm{C}_{2}, \mathrm{C}_{4}\right.$ connectivity). The ModRib isomer does not exhibit any specific fragment ion. However, these fragments cannot be explained by a specific disulfide opening for any of the connectivity isomers. Unfortunately, the 2-AA and 2-AB matrices did not yield any fragment ions (data not shown).

Even if, in the case of the mod-based peptides using the 1,5DAN matrix, connectivity-specific fragment ions could be found, this might not be the case for other disulfide bondcontaining peptides or when using other matrices (e.g., 2-AA and 2-AB). We therefore still go further into the ISD data exploitation by calculating the normalized intensities of the non-reduced $\left(\left[\mathrm{M}+1 \mathrm{H}^{+}\right]^{+}\right)$, partially disulfide-reduced $\left(\left[\mathrm{M}+2 \mathrm{H}+1 \mathrm{H}^{+}\right]^{+}\right)$and totally disulfide-reduced $([\mathrm{M}+$ $\left.4 \mathrm{H}+1 \mathrm{H}^{+}\right]^{+}$) parent ion species (cf. Eq. 1). In addition, for the 1,5-DAN matrix, given that the mod-based peptides yielded fragment ions after the ISD reaction, the normalized intensity of all fragment ions (sum of all fragments) can be calculated as well for each of the three isomers using the three different matrices. Equation 2 was then used to calculate the normalized intensities after isotope pattern deconvolutions; Eq. 2 illustrates the calculation of the normalized intensity of the non-reduced parent ion. The fragment ions were considered as sum of both $\left[\mathrm{M}+2 \mathrm{H}+1 \mathrm{H}^{+}\right]^{+}$and $\left[\mathrm{M}+4 \mathrm{H}+1 \mathrm{H}^{+}\right]^{+}$ion contributions given that the "model-peptide" fragments do most of the time not allow for the identification of its partially reduced or totally reduced nature (see Figure SI9, $c$-type fragments).

Intensity $_{\left[M+1 H^{+}\right]^{+}}(\%)=$

$\frac{\sum I_{\text {isotope pattern }}\left[M+1 H^{+}\right]^{+}}{\sum I_{\text {isotope pattern }}\left(\left[M+1 H^{+}\right]^{+},\left[M+2 H+1 H^{+}\right]^{+},\left[M+4 H+1 H^{+}\right]^{+}, \text {Fragments }\right)} * 100$

In order to verify the reproducibility of the measurements, the spectra of each peptide isomer (three matrices) were recorded 5 times ( 5 different days). Figure 5 depicts the normalized intensities for all considered species.

By calculating the $p$ values of the results obtained with the 2-AA and 2-AB matrices (see Figure SI10 and Figure SI11), it appears that no significant distinction between the isomers can be obtained ( $p$ values $>0.05$ ).

Concerning the 1,5-DAN matrix, the $\left[\mathrm{M}+1 \mathrm{H}^{+}\right]^{+}$and the $\left[\mathrm{M}+2 \mathrm{H}+1 \mathrm{H}^{+}\right]^{+}$species do not allow distinguishing between the isomers (see Figure SI12). However, the $\left[\mathrm{M}+4 \mathrm{H}+1 \mathrm{H}^{+}\right]^{+}$ species allow to distinguish the ModBea from the ModRib isomer ( $p$ value $=0.0298)$ and the ModBea from the ModGlo isomer $(p$ value $=0.0034)$. Moreover, when focusing on the fragments obtained with ISD, ModBea and ModGlo can also be distinguished ( $p$ value $=0.0186$ ). The fact that the fragment ion intensities enable the discrimination between isomers could be of great importance for disulfide bond connectivity identifications. Indeed, in the absence of connectivity-specific fragments, a qualitative look at the fragmentation spectra would not have allowed to distinguish the isomers. If, additionally, the parent ion species do not provide discriminative normalized intensities, fragment ion intensities, if present, could bring help.
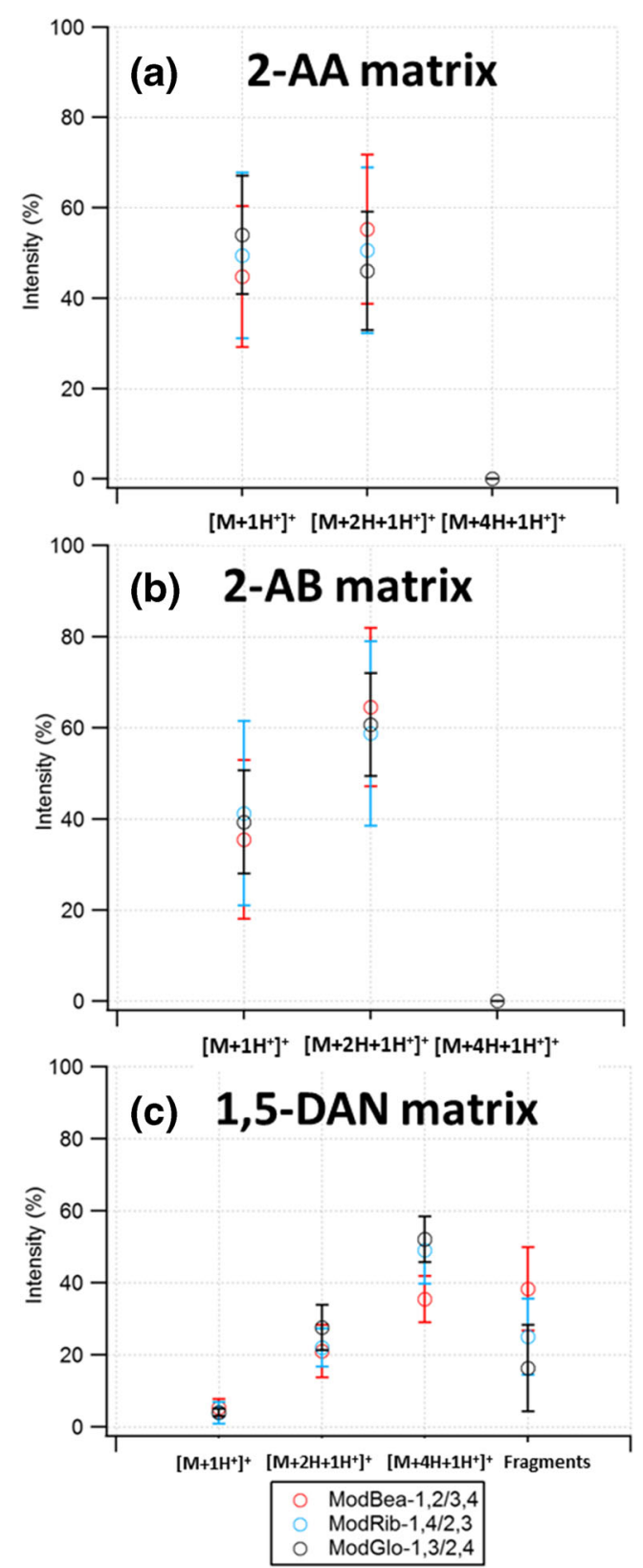

Figure 5. Calculated normalized intensities after isotope pattern deconvolution of the non-reduced parent ion $\left[\mathrm{M}+1 \mathrm{H}^{+}\right]^{+}$, of the partially reduced $\left[\mathrm{M}+2 \mathrm{H}+1 \mathrm{H}^{+}\right]^{+}$and the totally reduced $\left[\mathrm{M}+4 \mathrm{H}+1 \mathrm{H}^{+}\right]^{+}$parent ion species of mod-based peptides using (a) the 2-AA matrix (see Eq. 1), (b) the 2-AB matrix (see Eq. 1), and (c) the 1,5-DAN matrix. For the 1,5-DAN matrix, the normalized intensity of the fragment ions was calculated as well (Eq. 2). The error bars originate from the standard deviation of 5 independent measurements (5 different days) 


\section{Conclusions}

The aim of this study was to investigate the ability of MALDIISD to experimentally predict the disulfide connectivity of peptides bearing two intramolecular disulfide bonds. Different data analysis methods were developed in order to cover different potential scenarios of peptide fragmentation and disulfide reduction signals yielded by MALDI-ISD.

For this purpose, MALDI-ISD experiments were performed (5 replicates each on different days) on two series of peptides bearing the same sequence but differing cysteine connectivities using 3 different ISD matrices (2-AA, 2-AB, and 1,5-DAN). Generally, the 1,5-DAN matrix resulted in the highest disulfide bond reduction yield.

First, we interpreted the fragment ions yielded by the ISD process. Only few fragment ions after the 1,5-DAN ISD reduction were formed for the conotoxin-based peptides. They were non-specific to the connectivities (loss of $\mathrm{H}_{2} \mathrm{~S}$ and $\mathrm{CH}_{2} \mathrm{~S}_{2}$ ). For the Mod-based peptides, the 1,5-DAN matrix generated fragment ions, where some were found to be connectivity-specific (fragment ion peak at $m / z 999.4$ for the $\mathrm{C}_{1}, \mathrm{C}_{2} / \mathrm{C}_{3}, \mathrm{C}_{4}$ isomer and $m / z=2781.7$ for the $\mathrm{C}_{1}, \mathrm{C}_{3} / \mathrm{C}_{2}, \mathrm{C}_{4}$ isomer).

Then, given that one cannot expect to form specific fragment ions for all peptides through the ISD process, as seen for the conotoxin peptides, we tried further fragmenting the partially reduced parent ions (opening of one of the two disulfide bonds) using MS/MS (high energy CID). Unfortunately, MS/ MS (high energy CID) did not allow distinguishing between the different disulfide connectivities.

After interpreting the ISD and MS/MS (high energy CID) fragment ions, the disulfide-reduced parent ions were analyzed. Using isotope pattern deconvolutions, normalized intensities were calculated for the intact non-reduced parent ion, for the partially disulfide-reduced parent ion and for the totally reduced parent ion. Significant differences, taking into account the standard deviations from the replicate measurements (owing to $t$ tests), could thus be found in isomer-ISD reactivities. The conotoxin peptides were distinguishable using the 1,5$\mathrm{DAN}$ and the 2-AB matrices, in positive ionization mode. Regarding the Mod-based peptides, using the 1,5-DAN in conjunction with the 2-AB matrices allowed distinguishing disulfide connectivity isomers.

Finally, the calculation of the normalized intensities for the Mod-based peptides was expanded to their fragment ions formed using 1,5-DAN. This last result showed a distinction between ModBea and ModGlo peptides.

The obtained results pave the way for a quick and simple method for cysteine connectivity identification of peptides bearing two intramolecular disulfide bonds, without consuming much sample. However, the presented method necessitates the use of isomer standards of the chosen sequence to compare the normalized intensity plots with attributed connectivities. The positive MALDI-ISD analysis of such compounds using the 1,5-DAN matrix could also be useful for peptide sequencing without prior chemical disulfide reduction.
In terms of prospects, further ISD matrices having different reduction efficiencies could be tested and different peptides could be sampled to extend the presented data interpretation methodologies to other peptide sequences. The next step in the disulfide bond characterization could be the coupling of MALDI-ISD with ion mobility. Indeed, such analyses of the disulfide-reduced species and of the obtained fragment ions could then give a better understanding of their structures.

\section{Acknowledgments}

The authors thank the FRS-FNRS for the financial support (FRIA and instrumentation), the Fonds Européen de développement regional (FEDER), the Walloon region, and the European commission (F.P. 7 VENOMICS project) for financial support.

\section{Compliance with Ethical Standards}

Conflict of Interest The authors declare that they have no conflict of interest.

\section{References}

1. Lewis, R.J., Garcia, M.L.: Therapeutic potential of venom peptides. Nat. Rev. Drug Discov. 2, 790-802 (2003)

2. Craik, D.J., Daly, N.L., Bond, T., Waine, C.: Plant cyclotides: a unique family of cyclic and knotted proteins that defines the cyclic cystine knot structural motif. J. Mol. Biol. 294, 1327-1336 (1999)

3. Lindholm, P., Goransson, U., Johansson, S., Claeson, P., Gullbo, J., Larsson, R., Bohlin, L., Backlund, A.: Cyclotides: a novel type of cytotoxic agents. Mol. Cancer Ther. 1, 365-369 (2002)

4. Ganz, T.: Defensins: antimicrobial peptides of innate immunity. Nat. Rev. Immunol. 3, 710-720 (2003)

5. Lehrer, R.I., Ganz, T.: Antimicrobial peptides in mammalian and insect host defence. Curr. Opin. Immunol. 11, 23-27 (1999)

6. Góngora-Benítez, M., Tulla-Puche, J., Albericio, F.: Multifaceted roles of disulfide bonds. peptides as therapeutics. Chem. Rev. 114, 901-926 (2013)

7. Gray, W.R.: Disulfide structures of highly bridged peptides: a new strategy for analysis. Protein Sci. 2, 1732-1748 (1993)

8. Thornton, J.M.: Disulphide bridges in globular proteins. J. Mol. Biol. 151, 261-287 (1981)

9. Raina, S., Missiakas, D.: Making and breaking disulfide bonds. Annu. Rev. Microbiol. 51, 179-202 (1997)

10. Betz, S.F.: Disulfide bonds and the stability of globular proteins. Protein Sci. 2, 1551-1558 (1993)

11. Khakshoor, O., Nowick, J.S.: Use of disulfide "staples" to stabilize $\beta$ sheet quaternary structure. Org. Lett. 11, 3000-3003 (2009)

12. Cashman, T.J., Linton, B.R.: $\beta$-sheet hydrogen bonding patterns in cystine peptides. Org. Lett. 9, 5457-5460 (2007)

13. Leduc, A.-M., Trent, J.O., Wittliff, J.L., Bramlett, K.S., Briggs, S.L., Chirgadze, N.Y., Wang, Y., Burris, T.P., Spatola, A.F.: Helix-stabilized cyclic peptides as selective inhibitors of steroid receptor-coactivator interactions. Proc. Natl. Acad. Sci. U. S. A. 100, 11273-11278 (2003)

14. Santiveri, C.M., León, E., Rico, M., Jiménez, M.A.: Context-dependence of the contribution of disulfide bonds to $\beta$-hairpin stability. Chem. - A Eur. J. 14, 488-499 (2008)

15. Bock, J.E., Gavenonis, J., Kritzer, J.A.: Getting in shape: controlling peptide bioactivity and bioavailability using conformational constraints, (2013) 
16. Wu, Y., Wu, X., Yu, J., Zhu, X., Zhangsun, D., Luo, S.: Influence of disulfide connectivity on structure and bioactivity of $\alpha$-conotoxin TxIA. Molecules. 19, 966-979 (2014)

17. Benham, C.J., Jafri, M.S.: Disulfide bonding patterns and protein topologies. Protein Sci. 2, 41-54 (1993)

18. Walewska, A., Skalicky, J.J., Davis, D.R., Zhang, M.-M., Lopez-Vera, E., Watkins, M., Han, T.S., Yoshikami, D., Olivera, B.M., Bulaj, G.: NMR-based mapping of disulfide bridges in cysteine-rich peptides: application to the $\mu$-conotoxin SxIIIA. J. Am. Chem. Soc. 130, 14280 14286 (2008)

19. Mobli, M., King, G.F.: NMR methods for determining disulfide-bond connectivities. Toxicon. 56, 849-854 (2010)

20. Calvete, J.J., Schrader, M., Raida, M., McLane, M.A., Romero, A., Niewiarowski, S.: The disulphide bond pattern of bitistatin, a disintegrin isolated from the venom of the viper Bitis arietans. FEBS Lett. 416, 197202 (1997)

21. Bauer, M., Sun, Y., Degenhardt, C., Kozikowski, B.: Assignment of all four disulfide bridges in echistatin. J. Protein Chem. 12, 759-764 (1993)

22. Durand, K.L., Ma, X., Plummer, C.E., Xia, Y.: Tandem mass spectrometry (MSn) of peptide disulfide regio-isomers via collision-induced dissociation: utility and limits in disulfide bond characterization. Int. J. Mass Spectrom. 343-344, 50-57 (2013)

23. Durand, K.L., Ma, X., Xia, Y.: Intra-molecular reactions between cysteine sulfinyl radical and a disulfide bond within peptide ions. Int. J. Mass Spectrom. 378, 246-254 (2015)

24. Massonnet, P., Upert, G., Smargiasso, N., Gilles, N., Quinton, L., De Pauw, E.: Combined use of ion mobility and collision-induced dissociation to investigate the opening of disulfide bridges by electron-transfer dissociation in peptides bearing two disulfide bonds. Anal. Chem. 87, 5240-5246 (2015)

25. Tan, L., Durand, K.L., Ma, X., Xia, Y.: Radical cascades in electron transfer dissociation (ETD)-implications for characterizing peptide disulfide regio-isomers. Analyst. (2013)

26. Fukuyama, Y., Iwamoto, S., Tanaka, K.: Rapid sequencing and disulfide mapping of peptides containing disulfide bonds by using 1,5diaminonaphthalene as a reductive matrix. J. Mass Spectrom. 41, 191201 (2006)
27. Demeure, K., Gabelica, V., De Pauw, E.A.: New advances in the understanding of the in-source decay fragmentation of peptides in MALDITOF-MS. J. Am. Soc. Mass Spectrom. 21, 1906-1917 (2010)

28. Asakawa, D.: Principles of hydrogen radical mediated peptide/protein fragmentation during matrix-assisted laser desorption/ionization mass spectrometry. Mass Spectrom. Rev. (2014)

29. Yang, H., Liu, N., Liu, S.: Determination of peptide and protein disulfide linkages by MALDI mass spectrometry. Top. Curr. Chem. 331, 79-116 (2013)

30. Quinton L., Demeure K., Dobson R., Gilles N., Gabelica V., De Pauw E.: New method for characterizing highly disulfide-bridged peptides in complex mixtures: application to toxin identification from crude venoms. (2007)

31. Volker Schnaible, Stephan Wefing, Anja Resemann, Detlev Suckau, Anne Bücker, Sybille Wolf-Kümmeth, Hoffmann, D.: Screening for disulfide bonds in proteins by MALDI in-source decay and LIFT-TOF/ TOF-MS. (2002)

32. Hardouin, J.: Protein sequence information by matrix-assisted laser desorption/ionization in-source decay mass spectrometry. Mass Spectrom. Rev. 26, 672-682 (2007)

33. Massonnet, P., Haler, J.R.N.J.R.N., Upert, G., Degueldre, M., Morsa, D., Smargiasso, N., Mourier, G., Gilles, N., Quinton, L., De Pauw, E.: Ion mobility-mass spectrometry as a tool for the structural characterization of peptides bearing intramolecular disulfide bond(s). J. Am. Soc. Mass Spectrom. 27, 1637-1646 (2016)

34. Abdel Azzem, M., Yousef, U.S., Limosin, D., Pierre, G.: Electrooxidative oligomerization of 1,5-diaminonaphthalene in acetonitrile medium. J. Electroanal. Chem. 417, 163-173 (1996)

35. Smargiasso, N., Quinton, L., De Pauw, E.: 2-Aminobenzamide and 2aminobenzoic acid as new MALDI matrices inducing radical mediated insource decay of peptides and proteins. J. Am. Soc. Mass Spectrom. 23, 469-474 (2012)

36. Asakawa, D., Smargiasso, N., Quinton, L., De Pauw, E.: Peptide backbone fragmentation initiated by side-chain loss at cysteine residue in matrix-assisted laser desorption/ionization in-source decay mass spectrometry, (2013) 